NBER WORKING PAPER SERIES

\title{
THE OPIOID EPIDEMIC WAS NOT CAUSED BY ECONOMIC DISTRESS BUT BY FACTORS THAT COULD BE MORE RAPIDLY ADDRESSED
}

\author{
Janet Currie \\ Hannes Schwandt \\ Working Paper 27544 \\ http://www.nber.org/papers/w27544
NATIONAL BUREAU OF ECONOMIC RESEARCH
1050 Massachusetts Avenue
Cambridge, MA 02138
July 2020

This paper was written for a forthcoming American Association of Political and Social Science volume, "What has happened to the American Working Class since the Great Recession ? " to be edited by Timothy Smeeding, Michael Strain, and Jennifer Romich. We thank Molly Schnell for extremely helpful comments. All opinions are solely those of the authors. The views expressed herein are those of the authors and do not necessarily reflect the views of the National Bureau of Economic Research.

NBER working papers are circulated for discussion and comment purposes. They have not been peerreviewed or been subject to the review by the NBER Board of Directors that accompanies official NBER publications.

(C) 2020 by Janet Currie and Hannes Schwandt. All rights reserved. Short sections of text, not to exceed two paragraphs, may be quoted without explicit permission provided that full credit, including $\odot$ notice, is given to the source. 
The Opioid Epidemic Was Not Caused by Economic Distress But by Factors that Could be More Rapidly Addressed

Janet Currie and Hannes Schwandt

NBER Working Paper No. 27544

July 2020, Revised August 2020

JEL No. I12,I14

\begin{abstract}
Without the opioid epidemic, American life expectancy would not have declined prior to 2020. In turn, the epidemic was sparked by the development and marketing of a new generation of prescription opioids and provider behavior is still helping to drive it. There is little relationship between the opioid crisis and contemporaneous measures of labor market opportunity. Cohorts and areas that experienced poor labor market conditions do show lagged increases in opioid mortality, but the effect is modest relative to the scale of the epidemic. Instead, we argue that there are specific policies and features of the U.S. health care market that led to the current crisis. It will not be possible to quickly reverse depressed economic conditions, but it is possible to implement policies that would reduce the number of new opioid addicts and save the lives of many of those who are already addicted.
\end{abstract}

\author{
Janet Currie \\ Department of Economics \\ Center for Health and Wellbeing \\ 185A Julis Romo Rabinowitz Building \\ Princeton University \\ Princeton, NJ 08544 \\ and NBER \\ jcurrie@ princeton.edu \\ Hannes Schwandt \\ School of Education and Social Policy \\ Northwestern University \\ 2120 Campus Drive \\ Evanston, Il 60208 \\ and NBER \\ schwandt@northwestern.edu
}


Deaths due to drug overdoses, mainly involving opioids, have more than tripled since 1999 , reaching a peak of 70,000 deaths in 2017. The U.S. leads the world in consumption of opioids, accounting for $72.9 \%$ of sales of Oxycodone and similar drugs (United Nations, 2018). The number of deaths due to opioids dwarfs the toll from previous drug epidemics in the U.S. Figure 1 shows that mortality from opioids is so great, that without these deaths U.S. life expectancy would have continued to rise after 2013 instead of falling.

Figure 1: Actual and counterfactual life expectancy without deaths of despair

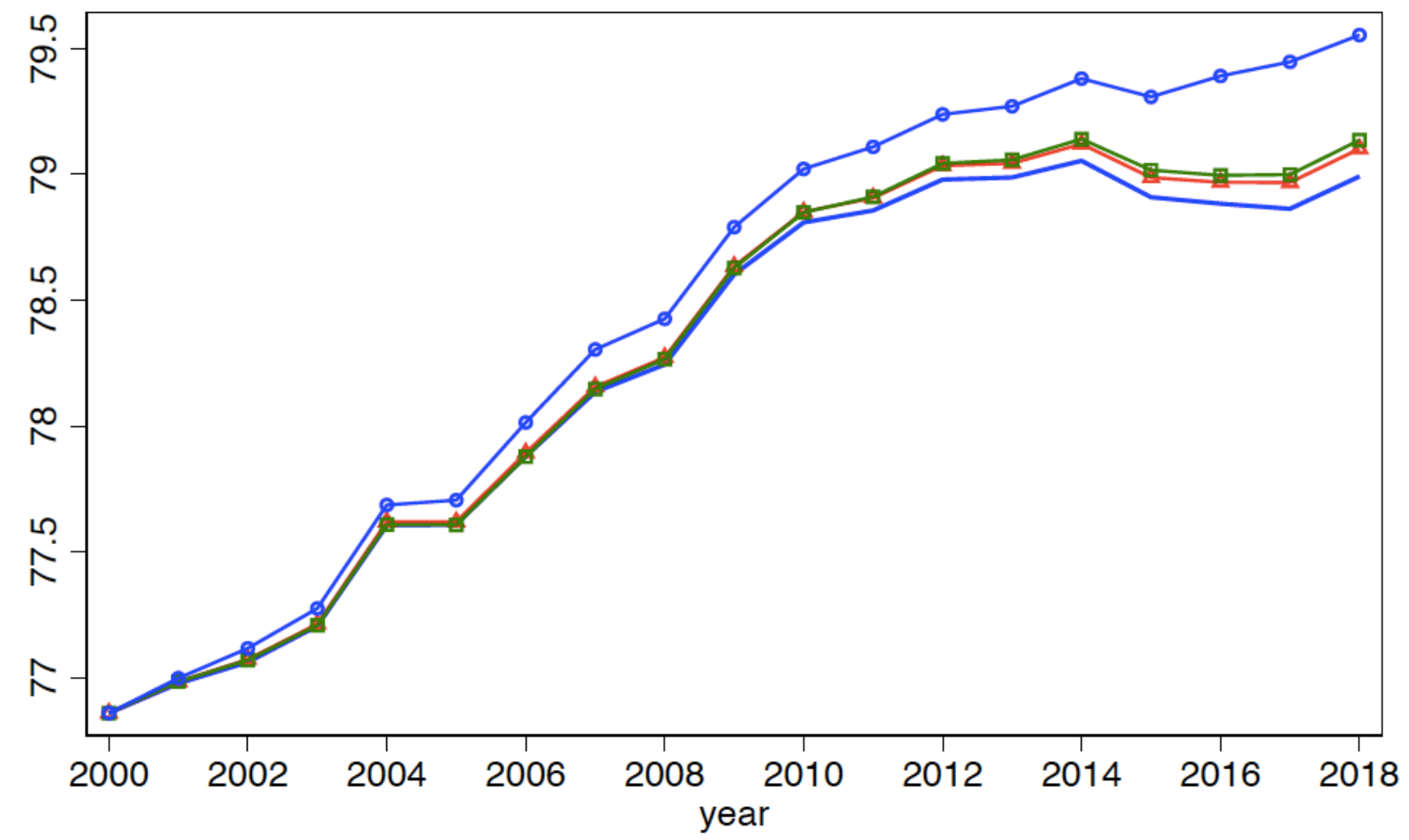

$\begin{array}{ll}- \text { actual life expectancy } & \nrightarrow \text { suicide rate constant at } 2000 \text { level } \\ ¥ \text { suicide + liver constant } & \rightarrow \text { suicide }+ \text { liver }+ \text { drug poisoning constant }\end{array}$

Notes: The blue solid line shows actual life expectancy over time. The three lines with triangle, square, and circle markers show counterfactual life expectancy estimates. The line with triangles assumes constant death rates for suicides at their 2000 level, the line with squares shows constant death rates for suicides and liver disease at their 2000 level, and the line with circles assumes constant death rates for suicides, liver disease and drug poisoning at their 2000 level. Source: Authors' calculations based on Vital Statistics mortality data.

The opioid epidemic is raging in all parts of society, but has hit poor and less educated people harder: Those with only a high school degree are 2.5 times more likely to die than people with a graduate degree, and people in poverty are 1.4 times more likely to die than people with incomes at or above five times the poverty line (Altekruse et al., 2020). It is often argued that opioid deaths are more common among people of lower socioeconomic status because low and declining status leads to opioid addiction and other deaths of despair (Case and Deaton, 2015). Yet, decades of research show that people of lower socioeconomic status are almost always at higher risk from a new health scourge, just as they are currently more likely to die from Covid- 
19. Poverty is like a drought in a wooded area-even given plenty of fuel, in order for there to be a forest fire there has to be a spark.

We argue that the development and marketing of a new generation of prescription opioids sparked the epidemic and that provider behavior is still helping to drive it. We first show that there is little relationship between the opioid crisis and contemporaneous measures of labor market opportunity. We next consider the relationship between opioids and labor market opportunity over the longer term. Cohorts and areas that experienced poor labor market conditions do show lagged increases in opioid mortality, but the effect is modest relative to the overall size of the epidemic. In the third section, we turn to the policies and features of the U.S. health care market that led to the current crisis. Understanding how we got here is extremely important because it shows that there is a lot of hope. It will not be possible to quickly reverse economic circumstances in depressed parts of the country, but it is possible to implement policies that would reduce the number of new opioid addicts and save the lives of many of those who are already addicted.

\section{Part 1: The relationship between opioid use and contemporaneous measures of employment, unemployment, and labor force participation}

Two ideas about the relationship between opioids and employment have become widely accepted. The first is that unemployment leads directly to opioid abuse. The second is that opioid abuse makes people unemployable. Both of these ideas have a grain of truth in them. For example, in a study of men in New Jersey who were out of the labor force, Krueger (2017) found that over 50\% reported taking prescription opioids daily. However, this does not prove that pain medication causes people to drop out of the labor force. For example, someone with chronic back pain might drop out of the labor force and then be prescribed opioids. In this case, the patient's back pain rather than opioid use is what caused them to leave the labor force.

Opioid use is not the main reason for declining labor force participation over time. Declines in male labor force participation among lower-skilled prime age men began well before the current opioid crisis. For example, Parsons (1980) pointed out that the share of men 45-54 who were not participating in the labor force rose from $4.2 \%$ to $8.4 \%$ between 1948 and 1976 with similar increases for other prime aged men. These trends reflect falling demand and low wages for less skilled workers combined with the growth of other sources of income support, such as disability payments (Council of Economic Advisors, 2016).

Declining labor force participation among women is a more recent phenomena. After growing from $43 \%$ to $78 \%$ of prime age women between 1962 and 2000, prime age female labor force participation fell to $75 \%$ in 2016 , with declines closer to 10 percentage points among women with a high school education or less. These recent declines parallel the ongoing declines in labor force participation among less skilled men, suggesting that in recent years similar forces have been at work for men and women (Black and Schanzenbach, 2017).

There is some support for the idea that unemployment can affect opioid use. For example, Venkataramani et al. (2020) found that areas where car plants had shut down experienced 
increases in opioid overdoses that became statistically significant by five years after the closing. And there are widespread reports of increases in overdoses during the COVID-19 pandemic, though it is somewhat unclear whether this reflects unemployment or the effects of lockdowns. Provisional data from the CDC indicates that from July 2019 to July 2020 overdose deaths increased 4.8\%, reversing what had been a declining trajectory since 2017 (CDC, 2020). Yet unemployment cannot be the major driver of the epidemic. The fraction employed in manufacturing declined steadily from $26.4 \%$ to $14.4 \%$ between 1970 and 2000 (U.S. Bureau of Labor Statistics, 2020) while the epidemic only began after 1997. The opioid epidemic first gained a foothold in the prosperous period prior to the recession of 2008. As the epidemic peaked in 2017-2018, unemployment was at its lowest level in decades. And while a great deal of attention has been focused on opioid deaths in depressed areas with persistently high unemployment, the majority of opioid deaths occurred in large states with low unemployment rates (Currie and Schnell, 2018). A final fact that does not fit the popular narrative is that although African-Americans have persistently high unemployment relative to other Americans, the epidemic seemed to start first among non-Hispanic whites, and had a particularly large impact on white women (Singhal, 2016).

Figure 2: Overdose deaths per 100,000 vs. unemployment rate, by state, 2018

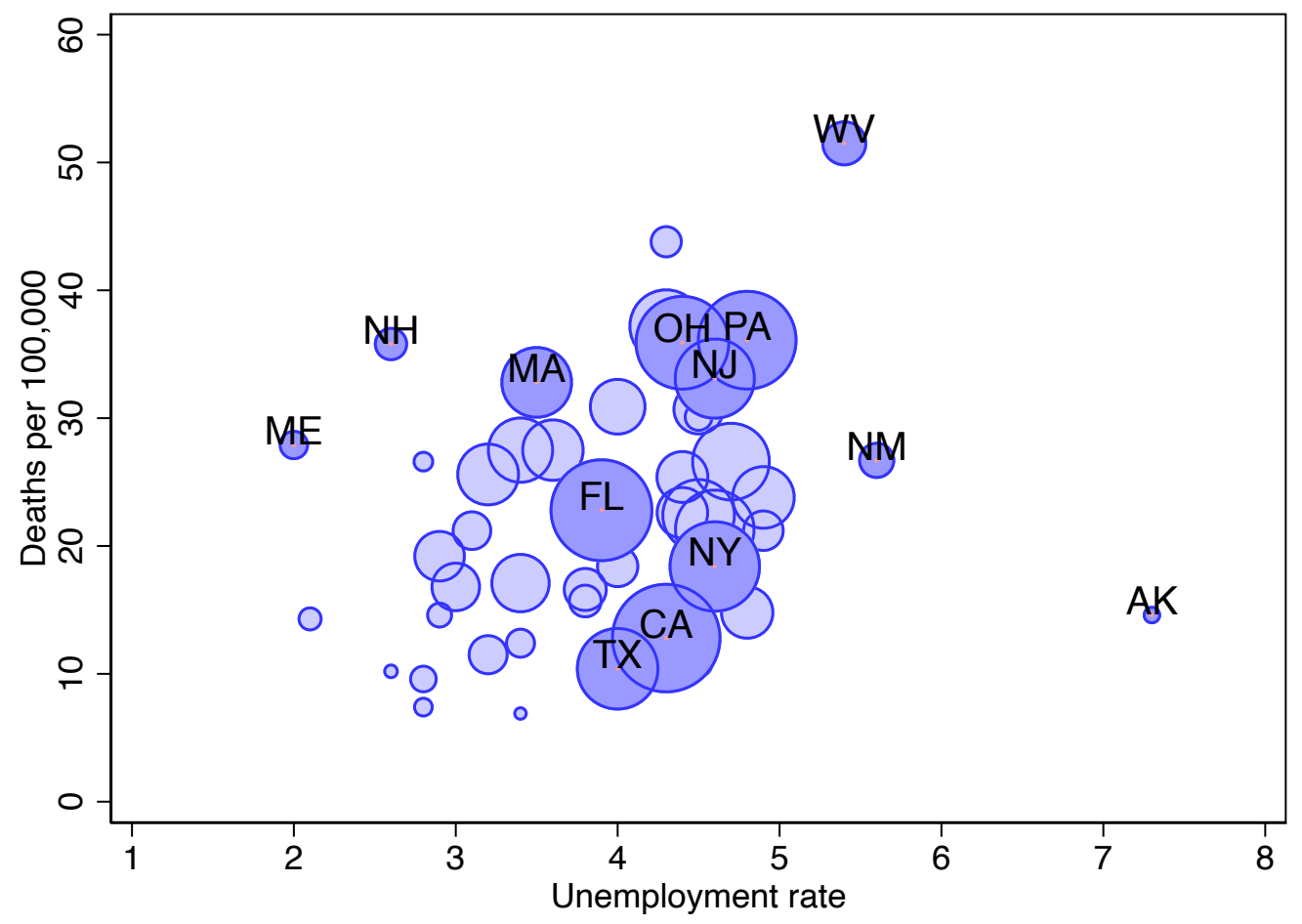

Notes: State-level data on unemployment for March 2018 is available here: https://www.bls.gov/opub/ted/2018/eight-states-at-historically-low-unemployment-rates-in-march-2018.htm. Data on overdose death rates and numbers of deaths in 2018 by state is available here:

https://www.cdc.gov/nchs/pressroom/sosmap/drug_poisoning_mortality/drug_poisoning.htm. Larger bubbles indicate more deaths. 
Figure 2 plots state opioid death rates in 2018 against the unemployment rate. The size of the bubbles indicates the number of deaths in each state. Seven states, California, Florida, Pennsylvania, Ohio, Texas, and New Jersey (in order of number of deaths) accounted for $42 \%$ of all of the opioid deaths in that year. The unemployment rates in all these states were very similar, even though in Ohio, the death rate was 35.9 per 100,000 and in Texas it was 10.4 per 100,000 . West Virginia fits the stereotype, with both relatively high unemployment and the highest death rate at 51.5 per 100,000 population. But other states are outliers in the other direction - for example both Massachusetts and New Hampshire had lower than average unemployment rates but high opioid death rates.

Furthermore, most people taking opioids are working. Currie, Jin, and Schnell (2019) analyze data from all retail pharmacies in the U.S. and find that $85 \%$ of the opioids prescribed for working aged people were paid for by private health insurance, which is employer provided. It is important to look at prescription opioids because most people who abuse opioids began with legally prescribed medications (Schnell, 2019). For example, 80\% of heroin users began by misusing prescription opioids (National Institute on Drug Abuse, 2020).

Even states with low unemployment have relatively depressed areas, so it is important to look at smaller geographies, like counties. Currie, Jin, and Schnell focus on the relationship between employment and opioid prescribing in the U.S. at the county level between 2006 and 2014. They look at employment rather than unemployment because unemployment rates come from national surveys that do not produce reliable county-level estimates. Employment data come from actual counts of people on the payroll because employers pay payroll taxes. The raw data actually show a positive relationship between employment and opioid prescribing at the county level, which is because people who are employed are more likely to have prescription drug insurance that covers opioids.

To ask whether changes in opioid prescribing affect employment, they use prescriptions for the elderly as an instrument for prescriptions for working aged adults. The underlying assumption is that higher prescribing for the elderly is correlated with higher prescribing for other groups, but has no direct effect on employment of prime aged adults. To examine the reverse question of whether changes in employment cause changes in opioid prescribing, they instrument employment changes using a shift-share instrument based on the idea that national employment shocks to say, the oil industry, will have a larger impact on oil producing regions.

They find that there is actually a small positive relationship between changes in opioid prescribing and changes in employment for females in areas with low levels of education. And there is no systematic relationship between changes in opioid prescribing and changes in employment rates for men. These results differ from some that have been reported in the literature for several reasons. ${ }^{1}$ First, they focus on the more accurate employment data rather

\footnotetext{
${ }^{1}$ Hollingsworth et al. (2017) report that a one percentage point increase in county unemployment rates is associated with a $3.55 \%$ increase in opioid fatalities. Carpenter et al. (2017) find that a one percentage-point increase in the state unemployment rate is associated with a 0.0004 percentage point increase in the probability of having a substance use disorder involving analgesics in the past year. Both studies include fixed effects but neither deals with of time varying omitted variables. Harris et al. (2019) find a large negative effect of opioid prescribing on employment-to-population ratios, using data on 10 states but do not include county fixed effects given a short time series (2013-2015).
} 
than on unemployment. Second, they use a longer time period and include county-level fixed effects to control for fixed long-term differences between counties (e.g. in Harlan County is different than San Diego in many ways). Third, they use all states, rather than a small subset. Fourth, they use instrumental variables to account for omitted time-varying third factors that could drive correlations between unemployment and opioid use.

Like much of the rest of the literature, Currie, Jin, and Schnell focus on prescription opioids, but in 2014 the number of deaths due to illegal opioids overtook the number of deaths due to prescription opioids. Still, Figure 2, deals with all opioid deaths and tells the same story - the relationship between opioid use and contemporaneous measures of labor force activity is weak. Hence, other factors must underlie the sharp increase in opioid deaths.

\section{Part 2: The relationship between longer-term measures of economic prospects and opioid deaths}

It might take years or even decades for economic disadvantage and socioeconomic decline to translate into addiction, sickness, and death. Several recent studies have taken a longer-term perspective - either by focusing on structural economic changes from import competition and automatization or by following unlucky cohorts of people who entered the labor market during recessions. Both approaches find that socioeconomic decline is linked to increases in opioid mortality, though the effects are quite small relative to the size of the problem.

\section{Impacts of structural change}

Autor, Dorn, and Hanson (2013) established that import competition originating from China's economic rise led to dramatic declines in U.S. manufacturing jobs. Autor, Dorn, Hanson (2018) find that when measured over decades, these reductions in manufacturing jobs increased mortality due to drug and alcohol poisonings. Pierce and Schott (2020) find similar effects of trade shocks on mortality in the twelve years following the U.S. granting of permanent normal trade relations to China in 2000. These effects are only present for non-Hispanic whites and are stronger for males, who were most impacted by trade-related declines in manufacturing. Adda and Fawaz (forthcoming) confirm these mortality results and document increases in illness and chronic pain. They point out that it is the persistence of these structural economic shocks that makes them deadly.

U.S. manufacturing jobs also declined due to automation and the rise of robotics. Charles, Hurst, and Schwartz (2019) use shift share instruments to analyze the mortality impacts of all of the shocks that affected national manufacturing activity and find positive effects on drug abuse and overdose deaths.

While this literature on structural change finds a relationship between manufacturing job losses and overdose deaths, economic decline cannot explain the magnitude of the opioid epidemic. For example, Pierce and Schott's (2020) estimates imply that a shift from the $25^{\text {th }}$ to the $75^{\text {th }}$ percentile of trade exposure can explain only up to $11.5 \%$ of the overall drug overdose deaths in 
2017. ${ }^{2}$ Charles, Hurst, and Schwartz (2019) caution that it is difficult to extrapolate their estimates to the aggregate since there may be confounding factors that they do not account for in their estimates. Ruhm (2019) does examine the role of confounding factors in the estimated relationship between economic decline and rising opioid deaths at the county level. He finds that after adding controls for counties' age and education structure, long-term changes in economic conditions explain at most one-ninth of the growth in overall drug-related mortality rates and very little of the variation in deaths due to prescription opioids. In other words, the epidemic has not been limited to areas experiencing negative structural change, but has raged in many other parts of the country that were not suffering such decline. For example, Bloom et al. (2019) show that the west coast and New England benefitted from Chinese import competition, but New Hampshire and Massachusetts have still been hit hard by opioids (Stopka et al., 2019).

\section{Long-run effects of business cycle fluctuations}

Business cycle fluctuations are another important source of economic dislocation. However, downturns are followed by upturns and it can be difficult to distinguish the impact of downturns on health outcomes in subsequent years. One group that bears the mark of temporary economic downturns for many years or even decades is new labor market entrants. Entering the labor market in a recession is associated with income losses that persist for years (Oyer, 2006; Kahn, 2010; Oreopoulos et al., 2012; Schwandt and von Wachter, 2019). For every percentage point increase in the local unemployment rate at labor market entry, recession graduates suffer an income loss of about $3 \%$ which fades out only over 10 to 15 years. $^{3}$

Schwandt and von Wachter (2020) link mortality rates for cohorts defined by their state and year of birth to the economic conditions these cohorts faced around labor market entry. To account for endogenous graduation timing and migration, the authors predict a cohort's graduation year and location using the average education and migration rates of surrounding cohorts. This setting allows the authors to analyze the causal impact of local recessions at labor market entry on mortality up to age 50 .

They find that affected cohorts have lower mortality which is driven by reductions in traffic and workplace accidents. (See also Ruhm, 2000; Miller et al., 2009; He, 2016; Strumpf et al., 2017). However, increases in mortality start to appear around 15 years after labor market entry and last over the rest of the time these cohorts can be followed. Unlucky cohorts are more likely to die of drug overdoses, liver disease, and other causes linked to poor health behaviors, such as heart disease and lung disease. Each percentage point increase in the unemployment rate at a cohort's labor market entry leads to a $2 \%$ increase in overall mortality and in deaths of despair. A

\footnotetext{
${ }^{2}$ Pierce and Schott (2020) find that an interquartile shift in trade exposure is associated with an increase of 2.5 drug overdose deaths per year. Overall age-adjusted U.S. drug overdose mortality was 21.7 in 2017.

${ }^{3}$ Recessions typically affect hiring more than firing. Those who enter the labor market in a downturn tend to start at lower-quality firms and take many years and repeated movements across firms to climb the job quality ladder and close the payment gap (Oreopoulos et al., 2012).
} 
moderate recession at labor market entry, increasing the unemployment rate by three percentage points, would therefore increase mortality in midlife by about $6 \%$.

The mortality impacts of entering the labor market during a recession are economically important but they explain only a small share of the overall increases in drug overdose deaths. Only a small number of cohorts over the past decades were hit by a recession at labor market entry. And even in the hypothetical case that all cohorts experienced a strong recession at graduation, the implied increase in opioid mortality would only amount to one-eighth of the overall opioid mortality increase observed in the past two decades (Schwandt and von Wachter, 2020, p.16).

\section{Part 3: The real causes of the opioid epidemic and policy responses}

As we have described, neither contemporaneous or long-term economic conditions can explain the severity of the U.S. opioid epidemic. This tragic situation is due to three factors. First, beginning in the late 1970s, new ideas about pain began circulating: Physicians began to believe that many patients suffered needlessly and that physicians had a duty to monitor and treat pain as "the fifth vital sign" (Wailoo, 2014). These changes were reflected in the rise of pain medicine as a specialty.

Second, companies like Purdue Pharma began aggressively marketing a new generation of opioids as a safe, non-addictive way to treat pain. Purdue spent hundreds of millions of dollars targeting doctors, hospitals, medical schools, and sponsored continuing medical education seminars which doctors take to maintain their accreditation (Van Zee, 2009). OxyContin, which was approved in 1995, was specifically promoted as safe for chronic pain as well as for conditions like wisdom tooth extraction. We now know that despite Purdue's claims, drugs like OxyContin are extremely addictive. For example, Barnett et al. (2017) showed that emergency room patients treated by doctors who were high prescribers of opioids were more likely to be taking opioids six months later than patients treated by low prescribers in the same hospitals, indicating that many people became addicted through a one-time exposure to the drugs.

Prior to the marketing push, most doctors had believed that opioids were too addictive and dangerous for anyone except terminally ill patients. Aggressive marketing by pharmaceutical companies changed those perceptions: Sales of opioid pain killers quadrupled between 1999 and 2013 (Paulozzi et al., 2011), fueling the rise in overdose deaths. Alpert et al. (2019) show that in states where OxyContin was marketed more aggressively, deaths rose faster. ${ }^{4}$ Deiana et al. (2020) show that companies marketed opioids more aggressively in years when raw material

\footnotetext{
${ }^{4}$ They exploit cross-state variation in the triplicate prescribing regulations that initially limited prescribing of OxyContin more in some states than others. Court documents that have come to light as a result of the lawsuit against Purdue show that less marketing was targeted to states with these programs, and that these states saw slower growth in overdoses even twenty years after the introduction of OxyContin.
} 
prices were lower (so that profit margins were higher) and that prescriptions rose more in places with more health care suppliers per capita.

Third, the U.S. is unusual in having little public oversight of medical prescribing in general, and of opioids in particular. Any doctor or dentist can prescribe opioids, and the maximum allowable dose is higher than in most other countries. Other countries require special training to prescribe opioids (Japan); require patients to register to use opioids (France, Italy, and Portugal); or require doctors to use special prescription pads for opioids (many countries) (Ho, 2019). Some countries with centralized health insurance systems do not cover opioids for non-cancer care, or to require pre-authorization for such uses. Countries with centralized health insurance systems may also cover alternative therapies, such as physical therapy for back problems, as a first line treatment. In the U.S. alternative therapies are often more expensive than prescription opioids and may not be covered by insurance.

\section{Physician prescribing practices as a key driver of the epidemic}

The result of these factors is that U.S. physicians prescribe too many opioids. ${ }^{5}$ Opioids are commonly prescribed in situations where other safer alternatives are available and where opioids are ineffective over the long term. For example, given that people build up tolerance to opioids, they are not suitable for non-terminal chronic pain, such as from back problems. According to the National Institute on Drug Abuse (2020) 21 to 29\% of patients prescribed opioids for chronic pain misuse them, between 8 and $12 \%$ develop an opioid use disorder, and 4 to $6 \%$ of those who misuse prescription opioids start taking heroin. Moreover, patients still frequently receive a 30day supply of opioids when a 3-day supply would likely suffice, creating a risk of both addiction and diversion to the secondary market. In 2016 the Centers for Disease Control belatedly issued guidelines in an attempt to curb these practices (Dowell et al., 2016). But these guidelines are not binding on U.S. physicians.

Why do physicians overprescribe? Some may simply be unaware of the dangers. Schnell and Currie (2018) show that physicians from higher-ranked medical schools prescribe fewer opioids, and that this effect is greater in specialties such as family medicine where doctors would be expected to have less training in pain management. ${ }^{6}$ In some cases, physician pay may be directly linked to patient satisfaction which in turn could be linked to successful pain management (Van Zee, 2009). It is possible that patients are influenced by direct-to-consumer advertising and ask for opioid pain medications - the U.S. is one of only three countries in the world that allow such advertising (Ventola, 2011). Some physicians may also use opioids as a way to compete for patients; taken to an extreme, this could lead to the "pill-mills" that became a feature of the American addiction landscape in the 2000s (Temple, 2015).

\footnotetext{
${ }^{5}$ U.S. physicians also over-prescribe addictive benzodiazepines relative to doctors in other
} countries. Taking benzodiazepines with opioids increases the probability of a fatal overdose (Sun et al., 2017).

${ }^{6}$ Doctors with little specialized training in pain medicine prescribe the majority of opioids in the U.S. 


\section{Policies to curb overprescribing}

The most concrete step so far towards reducing the abuse of prescription opioids is the development of state prescription drug monitoring programs (PDMPs). A PDMP is a statewide electronic database with information about the dispensing of all "scheduled" drugs including opioids. Dispensers must report information about patients, prescribers, and the drugs prescribed. PDMPs are meant to prevent "doctor shopping" by patients who collect multiple prescriptions from different doctors either for their own use or for resale. PDMPs were rolled out unevenly, and initially doctors were only encouraged rather than required to use them. Meara et al. (2016) found no effect of having a PDMP per se on opioid use (although her study focused on the disabled elderly rather than all opioid users). ${ }^{7}$ Buchmueller and Carey (2018), Anca et al. (2019), and Kaestner and Ziedan (2019) show that making PDMPs mandatory for doctors reduced opioid prescribing in states where this was done, though it has been more difficult to demonstrate reductions in deaths using a difference-in-differences framework. However, one should not expect changes in opioid prescribing behavior to instantaneously change the frequency of overdose deaths. Those who are already addicted to prescription pain medications may be driven to consume illegal opioids for example, and it takes time for people to spiral from initial addiction to overdoses and death. Similarly, the benefits of preventing addiction will only become clear over time. Still, PDMPs may be having an impact: opioid prescriptions peaked in 2012 at 81.3 per 100 people, and had fallen to 51.4 per 100 people by 2018 (Centers for Disease Control and Prevention, 2020).

PDMPs could potentially be used to identify physicians with improper prescribing behavior, in order to intervene to change their behavior, but this has rarely been done. Doctor et al. (2018) study a program in San Diego that linked death records to the PDMP in order to identify physicians who had prescribed opioids to patients who later overdosed. They show that informing physicians about these overdoses was effective in getting doctors to reduce their prescribing.

Schnell (2017) points out that it is important to not only crack down on the "secondary market" for pain pills that has sprung up (by implementing measures like the PDMPs), but to get doctors to reduce their unnecessary prescribing to legitimate patients as well. She shows that wellintentioned doctors may actually prescribe more opioids if they become less worried about pain pills being diverted to other users.

\section{Treatment of existing addiction}

Simply reducing prescriptions without addressing treatment could harm people who are already addicted to prescription opioids. An important natural experiment shows how consequential this effect could be. In 2010, OxyContin was reformulated to make it harder to abuse. Alpert et al.

\footnotetext{
${ }^{7}$ Horwitz et al. (forthcoming) also point out some issues in the literature on PDMPs, notably that it is difficult to determine exactly when the laws became effective, and that the laws differ considerably in their scope, not only with respect to whether use is mandatory (and for whom it is mandatory).
} 
(2018) and Evans et al. (2019) demonstrate that many OxyContin users switched to illegal opioids, and that as much as $80 \%$ of the increase in deaths due to heroin overdoses since 2010 is due to this reformulation. More recently, the U.S. market has been flooded with fentanyl, much of it made in China and Mexico and simply mailed to the U.S. in small packages, or smuggled as counterfeit pills. Fentanyl is much deadlier than heroin, since even tiny quantities kill (Jones et al., 2018). Mulligan (2020) emphasizes the role of prices and the fact that as fentanyl has entered the market, illegal opioids have gone from being more expensive than prescription opioids to being less expensive, spurring addicted users to switch to cheaper but more dangerous drugs. Prices are likely to respond to drug interdiction and enforcement activity, but it will be very difficult to stop the flow of fentanyl into the country without the cooperation of Chinese and Mexican authorities working to stop the production of the drug.

These considerations make effective treatment for opioid addiction an urgent public health priority. Unfortunately, less than $30 \%$ of people with a substance abuse problem receive treatment (Center for Behavioral Health Statistics and Quality, 2016). Moreover, many U.S. programs emphasize an "abstinence-only" approach, whereas medication-assisted treatment (MAT) with drugs such as buprenorphine is much more effective in terms of saving lives. Patients in abstinence-only treatment often overdose if they relapse, since they lose their tolerance for opioids. Ironically, while any U.S. doctor can prescribe opioids without any special training or oversight, doctors must obtain special licenses to prescribe MAT and are restricted in the number of patients they can treat (University of Michigan Behavioral Health Workforce Research Center, 2019).

One bright spot in terms of drug treatment policy in recent years has been the adoption of Naloxone Access Laws. These laws permit naloxone, an overdose-reversing drug, to be prescribed to "third parties," or make it available without a prescription. Rees et al. (2019) show that these laws reduced opioid deaths by 9 to $11 \%$, with the largest reduction coming from deaths due to prescription drugs. Moreover, the laws did not increase the use of opioids as some had feared.

What this means is that we must look at the opioid epidemic for what it is: A perfect storm that arose from a combination of newly available opioids, new attitudes about the importance of pain management, aggressive marketing, loose and decentralized prescribing practices, and lack of access to effective treatment. The solution to the problem must lie in addressing these root causes.

\section{Conclusions}

The implementation of mandatory PDMPs, new guidelines for opioid prescribing, and laws promoting naloxone have already made a dent in the epidemic. The number of overdoses fell $4.1 \%$ in 2018 relative to 2017 (Hedegaard et al., 2020), enough to cause life expectancy to have resumed its rising trend before the COVID-19 pandemic hit. However, in 2018, the prescribing rate was still 51.4 prescriptions per 100 persons (more than 168 million total opioid prescriptions). If 8 to $12 \%$ of those treated with opioids go on to develop an opioid use disorder, then our medical system is still generating many new addicts. 
Policies that would address these problems include reducing opioid prescriptions to "opioid naïve" patients, increasing access to non-addictive pain treatment, expanding the use of overdose-reversing drugs, and improving access to medication assisted treatment by removing barriers to its use. It took 20 years to get to where we are and the problem will not go away overnight. And the pandemic will complicate efforts to stem the tide. Yet, despite the overall rise in opioid overdose deaths during the pandemic, 15 states have continued to see declines (CDC, 2020). These continuing declines in states like New York, Vermont, and New Hampshire show that common-sense, evidence-based policies aimed at the opioid epidemic itself can save lives. 


\section{References}

Adda, J., Fawaz, Y. (Forthcoming). The health toll of import competition. Economic Journal.

Alpert, A., Evans, W., Lieber, E., Powell, D. (2019). Origins of the Opioid Crisis and its Enduring Impacts (NBER Working Paper No. 26500). Retrieved from the National Bureau of Economic Research: https://www.nber.org/papers/w26500

Alpert, A., Powell, D., Pacula, R. L. (2018). Supply-Side Drug Policy in the Presence of Substitutes: Evidence from the Introduction of Abuse-Deterrent Opioids. American Economic Journal: Economic Policy, 10 (4): 1-35.

Altekruse, S.F., Cosgrove, C.M., Altekruse, W.C., Jenkins, R.A., Blanco, C. (2020). Socioeconomic risk factors for fatal opioid overdoses in the United States: Findings from the Mortality Disparities in American Communities Study (MDAC). PLoS One, 15(1):e0227966.

Autor, D., Dorn, D., Hanson, G. (2018). When work disappears: Manufacturing decline and the falling marriage-market value of young men. American Economic Review: Insights.

Autor, D., Dorn, D., Hanson, G.H. (2013). The China syndrome: Local labor market effects of import competition in the United States. American Economic Review, 103(6), 2121-68.

Barnett, M. L., Olenski, A. R., Jena, A. B. (2017). Opioid-Prescribing Patterns of Emergency Physicians and Risk of Long-Term Use. The New England Journal of Msedicine, 376(7), 663673. https://doi.org/10.1056/NEJMsa1610524

Black, S., Schanzenbach, D. (2017). The Recent Decline in Women's Labor Force Participation. Brookings Papers on Economic Activity.

Bloom, N., Kurmann, A., Handley, K., Luck, P. (2019). The Impact of Chinese Trade on U.S. Employment: The Good, The Bad, and The Debatable.

Buchmueller, T.C., Carey, C. (2018). The Effect of Prescription Drug Monitoring Programs on Opioid Utilization in Medicare. American Economic Journal: Economic Policy, 10 (1): 77-112.

Carpenter, C. S., McClellan, C. B., Rees, D. I. (2017). Economic conditions, illicit drug use, and substance use disorders in the United States. Journal of Health Economics, 52, 63-73.

https://doi.org/10.1016/j.jhealeco.2016.12.009.

Case, A., Deaton, A. (2015). Rising Morbidity and Mortality in Midlife Among White NonHispanic Americans in the $21^{\text {st }}$ Century. Proceedings of the National Academy of Sciences, $112(49), 15078-15083$.

Center for Behavioral Health Statistics and Quality. (2016). Results from the 2015 national survey on drug use and health: Detailed tables. Rockville, MD: Substance Abuse and Mental Health Services Administration. 
Centers for Disease Control and Prevention, National Center for Injury Prevention and Control. (2020). U.S. Opioid Prescribing Rate Maps. Retrieved from CDC website:

cdc.gov/drugoverdose/maps/rxrate-maps.html.

Centers for Disease Control and Prevention (2020) Provisional Drug Overdose Death Counts as of July 5, 2020, https:/www.cdc.gov/nchs/nvss/vsrr/drug-overdose-data.htm, accessed August $10,2020$.

Charles, K.K., Hurst, E., Schwartz, M. (2019). The transformation of manufacturing and the decline in US employment. NBER Macroeconomics Annual, 33(1), 307-372.

Council of Economic Advisors. (2016). The Long-Term Decline in Prime-Age Male Labor Force Participation. Washington, DC: Executive Office of the President.

Currie, J., Jin, J., Schnell, M.K. (2019). US employment and opioids: Is there a connection? Research in Labor Economics, 47, 253-280.

Currie, J. and Schnell, M.K., 2018. A Closer Look at How the Opioid Epidemic Affects Employment. Harvard Business Review.

Deiana, C., Giua, L., Nistico, R. (2020). The Economics Behind the Epidemic: Afghan Opium Prices and Prescription Opioids in the U.S. (CSEF Working Paper 525).

Doctor, J.N., Nguyen, A., Lev, R., Lucas, J., Knight, T., Zhao, H., Menchine, M. ( 2018). Opioid Prescribing Decreases After Learning of a Patient's Fatal Overdose. Science, 10: 588590.

Dowell D., Haegerich, T. M., Chou, R. (2016). CDC Guideline for Prescribing Opioids for Chronic Pain - United States, 2016 (MMWR Recommendations and Reports; 65(No. RR-1):149). Retrieved from: https://www.cdc.gov/mmwr/volumes/65/rr/rr6501e1.htm

Evans, W., Lieber, E. M. J., Power, P. (2019). How the Reformulation of OxyContin Ignited the Heroin Epidemic. The Review of Economics and Statistics, 101:1-15.

Grecu, A. M., Dave, D. M., Saffer, H. (2019). Mandatory Access Prescription Drug Monitoring Programs and Prescription Drug Abuse. Journal of Policy Analysis and Management, John Wiley Sons, Ltd., 38(1), 181-209.

Harris, M. C., Kessler, L.M., Murray, M.N., Glenn, B. (2019). Prescription Opioids and Labor Market Pains: The Effect of Schedule II Opioids on Labor Force Participation and Unemployment. Journal of Human Resources.

He, M.M. (2016). Driving through the Great Recession: Why does motor vehicle fatality decrease when the economy slows down? Social Science Medicine, 155, 1-11. 
Hedegaard, H., Miniño, A.M., Warner, M. (2020). Drug Overdose Deaths in the United States, 1998-2018 (NCHS Data Brief No. 356). Retrieved from CDC:

https://www.cdc.gov/nchs/data/databriefs/db356-h.pdf

Ho, J. Y. (2019). The Contemporary American Drug Overdose Epidemic in International Perspective. Population and Development Review, 45(1):7-40.

Hollingsworth, A., Ruhm, C., Simon, K. (2017). Macroeconomic Conditions and Opioid Abuse. Journal of Health Economics, 56, 222-233.

Jones, C. M., Einstein, E. B., Compton, W. M. (2018). Changes in synthetic opioid involvement in drug overdose deaths in the United States, 2010-2016. JAMA, 319(17): 1819-1821.

Kaestner, R., Ziedan, E. (2019) Mortality and Socioeconomic Consequences of Prescription Opioids: Evidence from State Policies, NBER Working Paper \#26135

Kahn, L.B. (2010). The long-term labor market consequences of graduating from college in a bad economy. Labour Economics, 17(2), 303-316.

Krueger, A. (2017). Where have all the workers gone?: An Inquiry into the Decline of the U.S. Labor Force Participation Rate. Brookings Papers on Economic Activity.

Meara, E., Horwitz, J., Powell, W., McClelland, L., Zhou, W., O'Malley, J., Morden, N. (2016). State Legal Restrictions and Prescription Opioid Use among Disabled Adults. The New England Journal of Medicine, 375, 44-53.

Horwitz, Corey S. Davis, Lynn S. McClelland, Rebecca S. Fordon, Ellen Meara

Horwitz, J, Davis CS, McClelland LS, Fordon RS, Meara E, The Importance of Data Source in Prescription Drug Monitoring Program Research, Health Services Research, 2020. Forthcoming.

Miller, D.L., Page, M.E., Stevens, A.H. Filipski, M. (2009). Why are recessions good for your health? American Economic Review, 99(2), 122-27.

Mulligan, Casey. (2020) "Prices and Federal Policies in Opioid Markets," NBER Working paper \#26812

National Institute on Drug Abuse. (2020). Opioid Overdose Crisis (NIH: Washington D.C.). Retrieved from https://www.drugabuse.gov/drugs-abuse/opioids/opioid-overdose-crisis.

Oreopoulos, P., Von Wachter, T., Heisz, A. (2012). The short-and long-term career effects of graduating in a recession. American Economic Journal: Applied Economics, 4(1), 1-29.

Oyer, P. (2006). Initial labor market conditions and long-term outcomes for economists. Journal of Economic Perspectives, 20(3), 143-160. 
Parsons, D. (1980). The Decline in Male Labor Force Participation. Journal of Political Economy, 88(1): 117-134.

Paulozzi, L. J., Jones, C. M., Mack, K.A., Rudd, R. A. (2011). Vital signs: Overdoses of prescription opioid pain relievers - United States, 1999-2008 (Morbidity and Mortality Weekly Report 60: 1487- 1492). Retrieved from CDC:

https://www.cdc.gov/mmwr/preview/mmwrhtml/mm6043a4.htm

Pierce, J.R., Schott, P.K. (2020). Trade liberalization and mortality: evidence from US counties. American Economic Review: Insights, 2(1), 47-64.

Rees, D. I., Sabia, J. J., Argys, L. M., Dave, D., Latshaw, J. (2019). With a Little Help from My Friends: The Effects of Good Samaritan and Naloxone Access Laws on Opioid-Related Deaths. The Journal of Law and Economics, 62(1), 1-27.

Ruhm, C. J. (2000). Are recessions good for your health? The Quarterly Journal of Economics, $115(2), 617-650$.

Ruhm, C.J., (2019). Drivers of the fatal drug epidemic. Journal of Health Economics, 64, pp.2542.

Schnell, M. (2017). Physician Behavior in the Presence of a Secondary Market: The Case of Prescription Opioids (Working Paper).

Schnell, M. (2019). The Opioid Crisis: Tragedy, Treatments and Trade-offs. Institute for Economic Policy Research.

Schnell, M., Currie, J. (2018). Addressing the opioid epidemic: Is there a role for physician education? American Journal of Health Economics.

Schwandt, H., Von Wachter, T. M. (2019). Unlucky cohorts: Estimating the long-term effects of entering the labor market in a recession in large cross-sectional data sets. Journal of Labor Economics, 37(S1), S161-S198.

Schwandt, H. Von Wachter, T. M. (2020). Socioeconomic Decline and Death: Midlife Impacts of Graduating in a Recession (NBER Working Paper No. 26638). Retrieved from National Bureau of Economic Research website: https://www.nber.org/papers/w26638

Singhal, A., Tien, Y. Y., Hsia, R. Y. (2016). Racial-ethnic disparities in opioid prescriptions at emergency department visits for conditions commonly associated with prescription drug abuse. PloS one, 11(8).

Stopka, T.J., Jacque, E., Kelso, P., Guhn-Knight, H., Nolte, K., Hoskinson Jr, R., Jones, A., Harding, J., Drew, A., VanDonsel, A., Friedmann, P.D. (2019). The opioid epidemic in rural northern New England: An approach to epidemiologic, policy, and legal surveillance. Preventive Medicine, 128, 105740. 
Strumpf, E.C., Charters, T.J., Harper, S., Nandi, A. (2017). Did the Great Recession affect mortality rates in the metropolitan United States? Effects on mortality by age, gender and cause of death. Social Science Medicine, 189, 11-16.

Sun, E. C., Dixit, A., Humphreys, K., Darnall, B. D., Baker, L. C., Mackey, S. (2017). Association between concurrent use of prescription opioids and benzodiazepines and overdose: Retrospective analysis. $B M J, 356: \mathrm{j} 760$.

Temple, J. (2015). American pain. Guilford, Connecticut: Lyons Press.

United Nations, International Narcotics Control Board. (2016). Narcotic Drugs: Estimated World Requirements for 2018; Statistics for 2016 (Technical Report).

University of Michigan Behavioral Health Workforce Research Center and the National Council for Behavioral Health. (2019). Factors that Influence Access to Medication-Assisted Treatment. Ann Arbor, MI: UMSPH.

U.S. Bureau of Labor Statistics. (2020). Percent of Employment in Manufacturing in the United States [USAPEFANA]. Retrieved from FRED, Federal Reserve Bank of St. Louis:

https://fred.stlouisfed.org/series/USAPEFANA

Van Zee, A. (2009). The promotion and marketing of oxycontin: Commercial triumph, public health tragedy. American Journal of Public Health, 99(2): 221-227.

Venkataramani A. S., Bair, E. F., O’Brien, R. L., Tsai, A.C. (2020). Association Between Automotive Assembly Plant Closures and Opioid Overdose Mortality in the United States: A Difference-in-Differences Analysis. JAMA Internal Medicine., 180(2):254-262.

Ventola, C. L. (2011). Direct-to-consumer pharmaceutical advertising: Therapeutic or toxic? Pharmacy and Therapeutics, 36(10): 669-684.

Wailoo, K. (2014). Pain: A political history. Baltimore: Johns Hopkins University Press. 